\title{
Wanted Plasmodium falciparum, dead or alive
}

\author{
Fatimata Sow ${ }^{1}$, Mary Nyonda ${ }^{1}$, Anne-Lise Bienvenu ${ }^{1,2}$, Stephane Picot ${ }^{1,2, *}$ \\ ${ }^{1}$ University Claude Bernard Lyon 1, Malaria Research Unit, SMITh, ICBMS, UMR 5246 CNRS-INSA-CPE-UCBL1, 8 avenue Rockefeller, \\ 69373 Lyon cedex 08, France. \\ ${ }^{2}$ Hospices Civils de Lyon, Institut de Parasitologie et de Mycologie Médicale (IP2M), Hôpital de la Croix-Rousse, 103 grande rue de la \\ Croix-Rousse, 69317 Lyon cedex 04, France. \\ * Corresponding Author: Stephane Picot, E-mail: stephane.picot@univ-lyon1.fr
}

\begin{abstract}
Mechanisms of cell death in unicellular parasites have been subjects of debate for the last decade, with studies demonstrating evidence of apoptosis or non-apoptosis like mechanisms, including necrosis, and autophagy. Recent clarifications on the definition of regulated or accidental cell death by The Nomenclature Committee on Cell Death provides an opportunity to reanalyze some data, re-evaluate conclusions in the light of parasite diversity, and to propose alternative arguments in the context of malaria drug resistance, considering lack of really new drugs in the pipeline. Deciphering the mechanisms of death may help in detection of new drug targets and the design of innovative drugs. However, classifications have been evolving rapidly since initial description of "programmed cell death", leading to some uncertainty as to whether Plasmodium cell death is accidental or regulated.
\end{abstract}

\author{
doi: 10.15698/mic2015.07.211 \\ Received originally: 19.12.2014; \\ in revised form: 22.05.2015, \\ Accepted 25.05.2015 \\ Published 06.07.2015. \\ Keywords: Plasmodium, malaria \\ apoptosis, autophagy, cell death. \\ Abbreviations: \\ $C Q$-chloroquine, \\ MOMP - membrane permeabilization, \\ NCCD - nomenclature committee on \\ cell death, \\ $R C D$ - regulated cell death.
}

\section{INTRODUCTION}

Eugene Blank wrote years ago to the Lancet a few words from "The rape of Lucrece" where Shakespeare anticipated the existence of apoptosis [1]:

...showing life's triumph in the map of death, And death's dim look in life mortality...

But the drama of malaria is far from literature and requires more attention to the mechanisms of parasite death. Plasmodium falciparum causes malaria in millions of people each year, killing thousands, and leading to poverty and neurological sequelae for an undetermined number of others [2]. Members of the Plasmodium genus are more than two hundred, but only five species infect humans: $P$. falciparum, $P$. vivax, $P$. ovale, $P$. malariae and $P$. knowlesi. Most of the knowledge accumulated over the centuries is on $P$. falciparum. Interest in $P$. vivax is mounting due to several factors, first, it plays a role in severe malaria, second, it develops drug resistance, and third, it has persistent dormant liver forms placing it as a public health problem today and tomorrow [3]. Few non-human species have been studied as models on specific aspects of this disease. $P$. knowlesi has been known to humans since 1930, but molecular methods showed more recently that its circulation among humans is more frequent than earlier suspected [4]. Extensive knowledge is available about the major steps of the malaria parasite cycle in the human and the mosquito hosts, its biology, and the pathology it induces. On the contrary, very little is known about Plasmodium death, natural or induced by a physical, chemical or biological stress. Several mechanisms of cell death are known, including necrosis, apoptosis and autophagy, and these mechanisms have driven an increasing interest over the last two decades.

If a parasite has a "goal", it is that it be transmitted from host to host. Being responsible for morbidity or mortality is a collateral effect that precludes parasite transmission. High parasite virulence may lead to low transmissibility and sequentially low endemicity, for instance, killing its host before production of sexual forms which can be picked up by mosquitoes for continuity of the cycle, is a cost to parasite fitness. P. falciparum, is one of the most harmful of the malaria parasites. One could speculate that it has no inherent limitation to its transmission, leading to devastating disease in humans. On the other hand, one could reason that this unicellular parasite could be acting as a dispersed body within its vector and definitive host, either activating or not mechanisms that could regulate its virulence in terms of infectious burden. The most obvious of these potential mechanisms could be eliminating part of the parasite population in favour of host survival thus sustaining parasite transmission. Regulated cell death may be very well a cornerstone of this strategy. 


\section{PLASMODIUM CELL DEATH}

Crisis forms of the parasite were described in the early $20^{\text {th }}$ century, but these punctuated and condensed parasites were not extensively studied per se (approximately thirty publications). They were mostly considered as degenerating forms of the parasite induced by the immune response and the "crisis form factor" $[5,6]$. While examining with perplexity Plasmodium cultures decreasing in parasitemias under unknown reasons, we wondered whether these crisis forms were still alive. With regards to the first description of apoptosis in a protozoan parasite (Trypanosoma cruzi) by Ameisen in 1995 [7], we explored the notion that there was more to these crisis forms than parasite corpses. In 1997, we described the apoptosis-like DNA fragmentation of $P$. falciparum parasite in response to chloroquine (CQ) [8]. We speculated that resistance to chloroquine was related to inhibition of apoptosis. This first description of apoptosis in Plasmodium parasite was not readily accepted by colleagues, and regulated Plasmodium death still remains a controversial subject. More than fifteen years later, the debate is still ongoing, and requires to be revisited in light of recent progresses and issues. Among the current issues, recent evidence of artemisinin drug resistance of malaria parasites is a huge matter of concern. Artemisinin and its derivatives may act in part through the induction of parasite cell death via a redox mechanism. A parallel was made decades ago between resistance to regulated cell death (RCD) of cancer cells and choloroquine-resistance. The same paradigm could be used again for artemisinin-resistant parasites, with several issues to be addressed before global spreading of malaria parasite resistance.

\section{"TO DIE, TO SLEEP - NO MORE..."}

The Nomenclature committee on cell death (NCCD) is working to clearly delineate the boundaries between the various pathways leading to death of eukaryotic cells, this is in agreement with continuous progresses made on the mechanisms involved in metazoans $[9,10]$. Their work is useful to better knowledge in eukaryotic parasite life or death decisions. NCCD recently defined cell death as "accidental" or "regulated" [10]. Accidental cell death is caused by severe physical, chemical or mechanical insults. It is immediate and without possibility of prevention or regulation by drugs or genetics. It leads to the release of large amounts of damage-associated molecular patterns (DAMP). DAMPs are key danger signals that initiate an immune response and a pro-inflammatory cascade by activating Toll-like receptors (TLR) [11]. These TLR activators can also contribute to the pathogenesis of inflammatory diseases and cancer [11]. This model of accidental cell death of parasites could be used to define the death of microfilariae when treatments with full doses of Diethyl-carbamazine or ivermectine are used to treat patients presenting a high numbers of parasites.

RCD is based on the activity of complex molecular machinery, giving time to a competitive interplay between mechanisms involved in survival and those involved in death processes. Necrosis is neither the representative form for accidental cell death, nor apoptosis that for programmed cell death. The NCCD stressed the fact that RCD may present both apoptotic and necrotic traits, also that "autophagic cell death" should be used only from a functional perspective, and when RCD can be modulated by drugs or genetic intervention [12]. Features of autophagy are frequent during the different RCD processes, but their contribution to cellular demise seems to be limited $[13,14]$. Apoptosis is defined as a caspase dependant variant of RCD, triggered by intrinsic or extrinsic events. Apoptosis relies on the mitochondrial outer membrane permeabilization (MOMP) which requires activity of one of the proapoptotic BCL2 family member genes, balanced by the activity of anti-apoptotic members of the same family, under the control of $\mathrm{BH} 3$-only proteins. Apoptosis is highly controlled, thus reversible, as demonstrated by the role of metabolic check-points in their attempt to re-establish homeostasis [15]. Bcl2-like proteins may operate as central checkpoints of a network of "firebreaks" leading to "the point-of-no-return". Necroptosis is defined as a capaseindependent RCD initiated by death receptors. Parthanatos (caspase-independent cell death involving hyperactivation of poly (ADP-ribose) polymerases and AIF release) and ferroptosis (cell death induced by irondependant ROS accumulation through depletion of the antioxidant glutathione in neurons and cancer cells) are other forms of specific mechanisms leading to RCD [10].

It became clearer that cell adaptation to stress is a long-standing mechanism, with the potential of successive initiation of pathways with balanced effects, leading to or not the execution of the death machinery. Interestingly, two exclusive models of cell stress adaptation have been proposed. The conversion model described the succession of RCD-inhibitory signals after the insult, followed by RCDpromoting signals without overlap. The competition model speculates that the pro- and anti-RCD machineries are acting at the same time to favour either cell survival or cell death. This second model seems to be the most reliable for various conditions. These concepts, recently formulated and suspected by many researchers, may explain the abundance of the debate on the "who kills the cell?" scientific question.

Is it expected that new definition will lead to closure on the debate on how Plasmodium dies: Is it by necrosis, apoptosis, autophagy or some unknown phenomena? Will the clarification provided recently by the NCCD help to define the protozoan, and more specially the Plasmodium cell death? Do all these really matter?

\section{PLASMODIUM CRIME SCENE: NECROSIS, APOPTOSIS,} AUTOPHAGY?

In a recent opinion article, Proto and colleagues argued that protozoan cell death (including Leishmania, Trypanosoma, and Plasmodium) should only be considered as incidental cell death or unregulated necrosis [16]. Their opinion was mostly based on the fact that definitive evidence of machinery similar to eukaryotic cell is lacking in proto- 
zoan parasites. They argued that regulated cell death could only be demonstrated if the death process can be delayed or abolished by targeting key signalling or execution pathways [16]. But they also suggested that executioners and/or regulators could be specific in parasitic protozoa. This opinion is driven by extensive evidence from experts and seems to be convincing. Nevertheless, since differences between higher eukaryotic cells and protozoan parasites are obvious, should we look for regulated cell death through the same lens and tools used in parasites as those in higher eukaryotes, including humans? Is it acceptable to consider that, during evolution, a unicellular organism has selected a restricted biological armament essential to transmit advantages, abandoning unnecessary, finely regulated pathways, which are required for a multicellular organism to adapt to a considerable variety of external stresses? Finally, should we affirm that a biological evidence of RCD can exist without an already identified biochemical pathway is nonsense?

\section{PLASMODIUM APOPTOSIS}

The first description of $P$. falciparum apoptosis was made at a time when morphological features were the only markers of apoptosis [8]. P. berghei features of apoptosis including, condensation of chromatin, DNA fragmentation, and externalisation of phosphatidylserine were demonstrated a few years after that [17]. Evidence of Plasmodium apoptosis was obtained mostly in two different conditions. First, our primary description of apoptosis features in parasites subjected to chloroquine pressure opened the way to test the potential of other drugs to induce parasite apoptosis. Later on, Matthews and co-workers pointed out that the timing of exposure to drugs such as chloroquine has a major role for the detection of apoptosis markers [18]. It was also demonstrated that novel stilbenechalcone hybrids cause stage-specific apoptosis-like death with MOMP in $P$. falciparum ring stages and trophozoites [19].

Second, the parasite cell death was considered by Hurd and co-workers as a response to within-host environmental factor during mosquito's stages of the parasite. Several papers have provided evidence for expression of "classical" apoptosis markers under "natural" conditions at a parasite population level inside the mosquito.

The apoptosis machinery began to be depicted with the first description of $P$. falciparum metacaspase 1 (PfMCA1) [20]. The caspase-like cell death was specific to a $C Q$ sensitive clone. $z-V A D-f m k$ can restore $P$. falciparum proliferation under $C Q$ pressure and reduce the $C Q$ sensitivity of the parasite. Fascinatingly the $C Q$ resistant clone was insensitive to z-VAD-fmk indicating the CQ resistance level could be limited by other mechanisms. More recently, the metacaspase 1 gene was characterized in $P$. vivax isolates [21].

The expression of PfMCA1 C14 peptidase domain in yca1 deficient Saccharomyces cerevisiae led to a growth retardation and a drastic yeast cell death [22]. Of significance, this phenotype could be blocked by the addition of the pan caspase inhibitor z-VAD-fmk while PfMCA1 did not exhibit a caspase-like but an arginine protease activity, as reported for other protozoan MCAs [22]. PfMCA1 could play an initiator role leading to the activation of an aspartate protease effector. This hypothesis is in agreement with the description of PfMCA1 auto-processing leading to prodomain removal as it is typical of initiator caspases. PfMCA1 function seems to be finely regulated by two putative binding domains described: a C2 calcium-dependant membrane targeting domain and a CARD domain (Caspase Recruitment Domain) $[20,22,23]$. Authors suggested that the clan CA mediators are likely to be the proteases accounting for the cysteine protease activity [24].

Proteins with caspase-like activity were identified in the cytoplasm of the ookinete, and more than $50 \%$ of the mosquito midgut stages of the parasite die naturally by apoptosis before gut invasion. This phenomenon was prevented by a caspase inhibitor [17].

Following observations of pro- or contra- apoptosis evidences in Plasmodium parasites confirmed that the diversity is a cornerstone of cell death mechanism definition, and that different factors should be taken into consideration during the process of cell death characterization.

\section{ALL BUT APOPTOSIS!}

Using F32 P. falciparum clone (CQ sensitive), Nyakeriga et al. obtained a disparity of features associated with death induced in vitro by treatment with chloroquine, atovaquone, etoposide and L-penicillamine, without a complete panel of apoptosis markers for all drugs [25]. They failed to detect DNA degradation and concluded that Plasmodium cell death "is not associated with typical feature of apoptosis after treatment, which are characteristic of vertebrate cells". Using CSC-A (Honduras) P. falciparum clone, Porter et al. failed to detect typical physiological hallmarks of what they called "classical" apoptosis [26]. They concluded that apoptosis could be eliminated as a mechanism of Plasmodium death, and they consider that data presented in the first demonstration of $P$. falciparum apoptosis [8] were due to white blood cell contamination of the medium.

While nothing could be excluded definitively 15 years after the experiments were conducted, fresh parasite cultures were newly tested with blood controlled for the absence of leucocytes. Same blood was used to simultaneously cultivate two different clones, and apoptosis hallmarks were only observed with the $C Q$ sensitive clone. Examining blood smears twice a day for weeks would have revealed the suspected contamination by leucocytes. Returning to the raw data, parasitemias obtained during this period were as high as expected, leading to the hypothesis of the absence of leucocytes. Porter and colleagues then postulated that parasites were dying with signs of secondary necrosis, without a clear definition of these mechanism, and also stated that some form of programmed cell death could not be ruled out.

Using PSS1 (Brazil) P. falciparum clone (CQ resistant), Totino et al. failed to observe apoptosis after treatment 
with chloroquine and staurosporine, in agreement with our demonstration that drug resistance to $C Q$ may be linked to defect in apoptosis [27]. They observed a small percentage of TUNEL-positive parasites that they attributed to a small proportion of CQ sensitive parasite in the PSS1 resistance clone, but long-term cultivation could have selected a monoclonal culture. Finally they concluded that parasites were dying through an autophagic mechanism, on the basis of ultrastructural analysis that they considered a gold standard for identification of cell death procedure. Using $P$. berghei ANKA transgenic parasites (mCherry, GFP), Eickel et al. showed features of autophagy in liverstage parasites [28].

\section{PRO-APOPTOSIS CORNER}

Using 3D7 and 7G8 CQ sensitive and resistant $P$. falciparum clones, Picot et al. highlighted the first evidence of DNA fragmentation (DNA ladders and TUNEL), MOMP, PS exposure in $P$. falciparum erythrocytic stages $[8,20]$. The same team also described the $P$. falciparum metacaspase and its role in cell death [22]. Other studies using $P$. berghei ookinetes by Arambage et al. showed evidence of naturally occurring apoptosis in the mid gut of mosquitoes [29]. Muregi et al. also showed evidence of apoptosis by electron transmission microscopy and internucleosomal DNA fragmentation in parasites resistant to a thymidylate synthase inhibitor (5-fluoroorotate) [30]. In addition to these, using a 3D7 CQ sensitive $P$. falciparum clone, Rathore et al. elucidated features of apoptosis-like cell death (MOMP, caspase-like activity, dose dependant DNA fragmentation) by interfering with the ClpQY machinery [31]. Another study using $\mathrm{Dd} 2 \mathrm{CQ}$ sensitive $P$. falciparum clone by Mutai \& Waitumbi showed evidence of DNA fragmentation, MOMP, expression and translation of metacaspase gene under the effect of increasing parasitemia, suggesting existence of a quorum-sensing like mechanism [32]. Finally Cheema et al. used NF54 CQ sensitive $P$. falciparum clone to show evidence of MOMP, caspase activation and DNA fragmentation induced by Glaridin, a polyphenolic flavonoid [33].

\section{PLASMODIUM DEATH MODE: A QUESTION OF TIME?}

Recent work has demonstrated that among the erythrocytic stages of $P$. falciparum, response to heat will lead to apoptosis-like phenotype in the ring-stages, and an autophagy-like phenotype in late-stages of the parasite cycle. This provides more evidence that Plasmodium cell death is a fluctuant adaptation to stress, and that it will be difficult to clearly meet the definition criteria of regulated or accidental cell death [34]. The variability of the adaptive phenotypes of cell death in response to subtle changes of within-host environment was pointed out a few years ago [35]. In the absence of more detailed studies using a broad range of Plasmodium clones of different origins and with- out the aim of demonstrating the relevance of one cell death mechanism compared to others, there are few chances to obtain a balanced evidence of regulated cell death of Plasmodium parasite. One of the variables to be tested is the kinetics of Plasmodium cell death. It has become clear that the delay between the death message and cell demise is crucial. The complexity of pathways potentially involved could lead to changes in the cellular and biochemical manifestations of parasite death. Depending on the time plan of the tests performed to decipher parasite death mechanisms, markers could be different.

William Shakespeare also wrote "...for there is nothing either good or bad, but thinking makes it so..." and was cited earlier by Lipton \& Nakanishi [36]. The fantastic debates about mechanisms of Plasmodium death is of utmost importance for the development of future antimalarial drugs. Since scientific terminology is evolving rapidly, it could be counterproductive to reduce the mechanisms of death in Plasmodium parasite to a strict definition that will be outdated with increase in knowledge. The fight against malaria disease and its unacceptable toll of children and adults deaths requires a rapid development of innovative treatment to address the issues of increasing drug resistance. The Achilles' heel of the parasite could be its sensitivity to regulated cell death, providing new drug targets that we expected from the first observation of Plasmodium DNA fragmentation. There is probably a gap to fulfil between academic research needed to decipher the mechanisms of cell death in Plasmodium parasite, and clinical research needed to improve the outcome of malaria patients. Decades ago, Chloroquine and Quinine have been successfully used to treat patient without definitive knowledge on their mechanisms of action. It is tempting to speculate that there is enough evidence of regulated cell death for a translational research with the aim of designing new drugs to specifically kill parasites using the apoptosisautophagy machinery.

\section{CONFLICT OF INTEREST}

All authors read and approved the final manuscript. The authors declare that they have no competing interests.

\section{COPYRIGHT}

(C) 2015 Sow et al. This is an open-access article released under the terms of the Creative Commons Attribution (CC BY) license, which allows the unrestricted use, distribution, and reproduction in any medium, provided the original author and source are acknowledged.

Please cite this article as: Fatimata Sow, Mary Nyonda, Anne-Lise Bienvenu, Stephane Picot (2015). Wanted Plasmodium falciparum, dead or alive. Microbial Cell 2(7): 219-224. doi: 10.15698/mic2015.07.211 


\section{REFERENCES}

1. Blank E (1998). Shakespeare on apoptosis. The Lancet 351: 840.

2. White NJ, Pukrittayakamee S, Hien TT, Faiz MA, Mokuolu OA, and Dondorp AM (2014). Malaria. Lancet 383(9918): 723-735.

3. Shanks GD and White NJ (2013). The activation of vivax malaria hypnozoites by infectious diseases. Lancet Infect Dis 13(10): 900-906.

4. Müller $M$ and Schlagenhauf $P$ (2014). Plasmodium knowlesi in travellers, update 2014. Int J Infect Dis IJID Off Publ Int Soc Infect Dis 22: 55-64.

5. Ockenhouse CF, Schulman S, and Shear HL (1984). Induction of crisis forms in the human malaria parasite Plasmodium falciparum by gamma-interferon-activated, monocyte-derived macrophages. J Immunol Baltim Md 1950 133(3): 1601-1608.

6. Jensen JB, Boland MT, and Akood M (1982). Induction of crisis forms in cultured Plasmodium falciparum with human immune serum from Sudan. Science 216(4551): 1230-1233.

7. Ameisen JC, Idziorek T, Billaut-Mulot $O$, Loyens $M$, Tissier JP, Potentier A, and Ouaissi A (1995). Apoptosis in a unicellular eukaryote (Trypanosoma cruzi): implications for the evolutionary origin and role of programmed cell death in the control of cell proliferation, differentiation and survival. Cell Death Differ 2(4): 285-300.

8. Picot S, Burnod J, Bracchi V, Chumpitazi BF, and Ambroise-Thomas $\mathrm{P}$ (1997). Apoptosis related to chloroquine sensitivity of the human malaria parasite Plasmodium falciparum. Trans R Soc Trop Med Hyg 91(5): 590-591.

9. Kroemer G, Galluzzi L, Vandenabeele P, Abrams J, Alnemri ES, Baehrecke EH, Blagosklonny MV, El-Deiry WS, Golstein P, Green DR, Hengartner M, Knight RA, Kumar S, Lipton SA, Malorni W, Nuñez G, Peter ME, Tschopp J, Yuan J, Piacentini M, Zhivotovsky B, Melino G, and Nomenclature Committee on Cell Death 2009 (2009). Classification of cell death: recommendations of the Nomenclature Committee on Cell Death 2009. Cell Death Differ 16(1): 3-11.

10. Galluzzi L, Vitale I, Abrams JM, Alnemri ES, Baehrecke EH, Blagosklonny MV, Dawson TM, Dawson VL, El-Deiry WS, Fulda S, Gottlieb E, Green DR, Hengartner MO, Kepp O, Knight RA, Kumar S, Lipton SA, Lu X, Madeo F, Malorni W, Mehlen P, Nuñez G, Peter ME, Piacentini M, Rubinsztein DC, Shi $Y$, Simon $\mathrm{H}-\mathrm{U}$, Vandenabeele $\mathrm{P}$, White E, Yuan J, Zhivotovsky B, Melino G, and Kroemer G (2012). Molecular definitions of cell death subroutines: recommendations of the Nomenclature Committee on Cell Death 2012. Cell Death Differ 19(1): 107-120.

11. Łagiedo M, Sikora J, and Kaczmarek M (2015). Damage associated molecular patterns in the course of lung cancer - a review. Scand J Immunol.

12. Galluzzi L, Bravo-San Pedro JM, Vitale I, Aaronson SA, Abrams JM, Adam D, Alnemri ES, Altucci L, Andrews D, Annicchiarico-Petruzzelli M, Baehrecke EH, Bazan NG, Bertrand MJ, Bianchi K, Blagosklonny MV, Blomgren K, Borner C, Bredesen DE, Brenner C, Campanella M, Candi E, Cecconi F, Chan FK, Chandel NS, Cheng EH, Chipuk JE, Cidlowski JA, Ciechanover A, Dawson TM, Dawson VL, De Laurenzi V, De Maria R, Debatin K-M, Di Daniele N, Dixit VM, Dynlacht BD, El-Deiry WS, Fimia GM, Flavell RA, Fulda S, Garrido C, Gougeon M-L, Green DR, Gronemeyer H, Hajnoczky G, Hardwick JM, Hengartner MO, Ichijo H, Joseph B, Jost PJ, Kaufmann T, Kepp O, Klionsky DJ, Knight RA, Kumar $S$, Lemasters JJ, Levine B, Linkermann A, Lipton SA, Lockshin RA, LópezOtín C, Lugli E, Madeo F, Malorni W, Marine J-C, Martin SJ, Martinou JC, Medema JP, Meier P, Melino S, Mizushima N, Moll U, MuñozPinedo C, Nuñez G, Oberst A, Panaretakis T, Penninger JM, Peter ME, Piacentini M, Pinton $P$, Prehn JH, Puthalakath $H$, Rabinovich GA, Ravichandran KS, Rizzuto R, Rodrigues CM, Rubinsztein DC, Rudel T, Shi $\mathrm{Y}$, Simon $\mathrm{H}-\mathrm{U}$, Stockwell BR, Szabadkai G, Tait SW, Tang HL, Tavernarakis N, Tsujimoto $\mathrm{Y}$, Vanden Berghe $\mathrm{T}$, Vandenabeele $\mathrm{P}$,
Villunger A, Wagner EF, Walczak H, White E, Wood WG, Yuan J, Zakeri Z, Zhivotovsky B, Melino G, and Kroemer G (2015). Essential versus accessory aspects of cell death: recommendations of the NCCD 2015. Cell Death Differ 22(1): 58-73.

13. Denton D, Aung-Htut MT, Lorensuhewa N, Nicolson S, Zhu W, Mills K, Cakouros D, Bergmann A, and Kumar S (2013). UTX coordinates steroid hormone-mediated autophagy and cell death. Nat Commun 4: 2916.

14. Denton D, Aung-Htut MT, and Kumar S (2013). Developmentally programmed cell death in Drosophila. Biochim Biophys Acta 1833(12): 3499-3506.

15. Green DR, Galluzzi L, and Kroemer G (2014). Cell biology. Metabolic control of cell death. Science 345(6203): 1250256.

16. Proto WR, Coombs GH, and Mottram JC (2013). Cell death in parasitic protozoa: regulated or incidental? Nat Rev Microbiol 11(1): 58-66.

17. Al-Olayan EM, Williams GT, and Hurd H (2002). Apoptosis in the malaria protozoan, Plasmodium berghei: a possible mechanism for limiting intensity of infection in the mosquito. Int J Parasitol 32(9): 1133-1143.

18. Matthews $H$, Ali M, Carter V, Underhill A, Hunt J, Szor H, and Hurd $H$ (2012). Variation in apoptosis mechanisms employed by malaria parasites: the roles of inducers, dose dependence and parasite stages. Malar J 11: 297.

19. Sharma N, Mohanakrishnan D, Shard A, Sharma A, Saima null, Sinha AK, and Sahal D (2012). Stilbene-chalcone hybrids: design, synthesis, and evaluation as a new class of antimalarial scaffolds that trigger cell death through stage specific apoptosis. J Med Chem 55(1): 297-311.

20. Meslin B, Barnadas C, Boni V, Latour C, De Monbrison F, Kaiser K, and Picot $S$ (2007). Features of apoptosis in Plasmodium falciparum erythrocytic stage through a putative role of PFMCA1 metacaspaselike protein. J Infect Dis 195(12): 1852-1859.

21. Rezanezhad H, Menegon M, Sarkari B, Hatam GR, and Severini C (2011). Characterization of the metacaspase 1 gene in Plasmodium vivax field isolates from southern Iran and Italian imported cases. Acta Trop 119(1): 57-60.

22. Meslin B, Beavogui $A H$, Fasel N, and Picot $S$ (2011). Plasmodium falciparum metacaspase PfMCA-1 triggers a z-VAD-fmk inhibitable protease to promote cell death. PloS One 6(8): e23867.

23. Le Chat L, Sinden RE, and Dessens JT (2007). The role of metacaspase 1 in Plasmodium berghei development and apoptosis. Mol Biochem Parasitol 153(1): 41-47.

24. Ch'ng J-H, Kotturi SR, Chong AG-L, Lear MJ, and Tan KS-W (2010). A programmed cell death pathway in the malaria parasite Plasmodium falciparum has general features of mammalian apoptosis but is mediated by clan CA cysteine proteases. Cell Death Dis 1: e26.

25. Nyakeriga AM, Perlmann $H$, Hagstedt $M$, Berzins $K$, TroyeBlomberg M, Zhivotovsky B, Perlmann P, and Grandien A (2006). Druginduced death of the asexual blood stages of Plasmodium falciparum occurs without typical signs of apoptosis. Microbes Infect Inst Pasteur 8(6): 1560-1568.

26. Porter H, Gamette MJ, Cortes-Hernandez DG, and Jensen JB (2008). Asexual blood stages of Plasmodium falciparum exhibit signs of secondary necrosis, but not classical apoptosis after exposure to febrile temperature (40 C). J Parasitol 94(2): 473-480. 
27. Totino PRR, Daniel-Ribeiro CT, Corte-Real $S$, and de Fátima Ferreira-da-Cruz M (2008). Plasmodium falciparum: erythrocytic stages die by autophagic-like cell death under drug pressure. Exp Parasitol 118(4): 478-486.

28. Eickel N, Kaiser G, Prado M, Burda P-C, Roelli M, Stanway RR, and Heussler VT (2013). Features of autophagic cell death in Plasmodium liver-stage parasites. Autophagy 9(4): 568-580.

29. Arambage SC, Grant KM, Pardo I, Ranford-Cartwright L, and Hurd H (2009). Malaria ookinetes exhibit multiple markers for apoptosislike programmed cell death in vitro. Parasit Vectors 2(1): 32.

30. Muregi FW, Ohta I, Masato U, Kino H, and Ishih A (2011). Resistance of a rodent malaria parasite to a thymidylate synthase inhibitor induces an apoptotic parasite death and imposes a huge cost of fitness. PloS One 6(6): e21251.

31. Rathore S, Jain S, Sinha D, Gupta M, Asad M, Srivastava A, Narayanan MS, Ramasamy G, Chauhan VS, Gupta D, and Mohmmed A (2011). Disruption of a mitochondrial protease machinery in Plasmodium falciparum is an intrinsic signal for parasite cell death. Cell Death Dis 2: e231.
32. Mutai BK and Waitumbi JN (2010). Apoptosis stalks Plasmodium falciparum maintained in continuous culture condition. Malar J 9 Suppl 3: S6.

33. Cheema HS, Prakash O, Pal A, Khan F, Bawankule DU, and Darokar MP (2014). Glabridin induces oxidative stress mediated apoptosis like cell death of malaria parasite Plasmodium falciparum. Parasitol Int 63(2): 349-358.

34. Engelbrecht D and Coetzer TL (2013). Turning up the heat: heat stress induces markers of programmed cell death in Plasmodium falciparum in vitro. Cell Death Dis 4: e971.

35. Pollitt LC, Colegrave N, Khan SM, Sajid M, and Reece SE (2010). Investigating the evolution of apoptosis in malaria parasites: the importance of ecology. Parasit Vectors 3: 105.

36. Lipton SA and Nakanishi N (1999). Shakespeare in love--with NMDA receptors? Nat Med 5(3): 270-271. 